\title{
Orthotopic heart transplantation with reconstruction of persistent left superior vena cava
}

\author{
Kazuma Handa, Hiroki Hata, ${ }^{*}$ Koichi Toda, Shigeru Miyagawa, Yasushi Yoshikawa, Daisuke Yoshioka and \\ Yoshiki Sawa
}

\begin{abstract}
Background: Persistent left superior vena cava is a not uncommon congenital vascular abnormality. We report a case of heart transplantation with reconstruction of persistent left superior vena cava using a prosthetic vascular graft.

Case presentation: A 20-year-old man with idiopathic dilated cardiomyopathy and persistent left superior vena cava underwent orthotopic heart transplantation 2 years and 3 months after left ventricular assist device implantation. Because the persistent left superior vena cava had a larger diameter than the right superior vena cava, the transected persistent left superior vena cava was reconstructed with a prosthetic vascular graft anastomosed to the free wall of the right atrium. Postoperative enhanced computed tomography revealed good patency of the graft. The patient's postoperative course has been uneventful during 2 years of follow-up, despite the risk of complications.
\end{abstract}

Conclusions: Reconstruction of a persistent left superior vena cava with a prosthetic vascular graft may be one option at the time of heart transplantation.

Keywords: Persistent left superior vena cava, Orthotopic heart transplantation

\section{Background}

Persistent left superior vena cava (PLSVC) is a not an uncommon congenital vascular abnormality (incidence of $0.3-0.5 \%$ in the general population and $3-10 \%$ among those with congenital heart anomalies) [1]. This condition is usually asymptomatic and does not cause hemodynamic changes [2]. Prior case reports have described orthotopic heart transplantation in patients with PLSVC. In some of these cases, simple ligation of the PLSVC was performed, whereas in others the PLSVC was reconstructed [3-5]. We herein report a case of PLSVC reconstruction using a prosthetic vascular graft in a patient undergoing heart transplantation.

\footnotetext{
*Correspondence: hatahiro@surg1.med.osaka-u.ac.jp

Department of Cardiovascular Surgery, Osaka University Graduate School of Medicine, 2-2 Yamadaoka, Suita, Osaka 565-0871, Japan
}

\section{Case report}

A 20-year-old man diagnosed with idiopathic dilated cardiomyopathy presented with deteriorated cardiac function (left ventricular (LV) ejection fraction 18\%). After registration with the Japan Organ Transplant network, he underwent continuous-flow LV assist device (LVAD) implantation as a bridge to transplantation. When a donor in good condition was found 2 years and 3 months after LVAD implantation, we decided to perform heart transplantation. The PLSVC and atresia of the left brachiocephalic vein ( $\mathrm{LBCV}$ ) were recognized on preoperative chest computed tomography (Fig. 1). Because the right superior vena cava (SVC) seemed larger than the PLSVC, we initially planned to ligate the PLSVC.

After full median sternotomy and dissection around the heart, we found that, contrary to our expectations, the PLSVC had a larger diameter than the right SVC. Therefore, we decided to reconstruct the PLSVC instead of ligating it. We established cardiopulmonary bypass by

\section{Springer Open}

(c) The Author(s). 2020 Open Access This article is licensed under a Creative Commons Attribution 4.0 International License, which permits use, sharing, adaptation, distribution and reproduction in any medium or format, as long as you give appropriate credit to the original author(s) and the source, provide a link to the Creative Commons licence, and indicate if changes were made. The images or other third party material in this article are included in the article's Creative Commons licence, unless indicated otherwise in a credit line to the material. If material is not included in the article's Creative Commons licence and your intended use is not permitted by statutory regulation or exceeds the permitted use, you will need to obtain permission directly from the copyright holder. To view a copy of this licence, visit http://creativecommons.org/licenses/by/4.0/. 


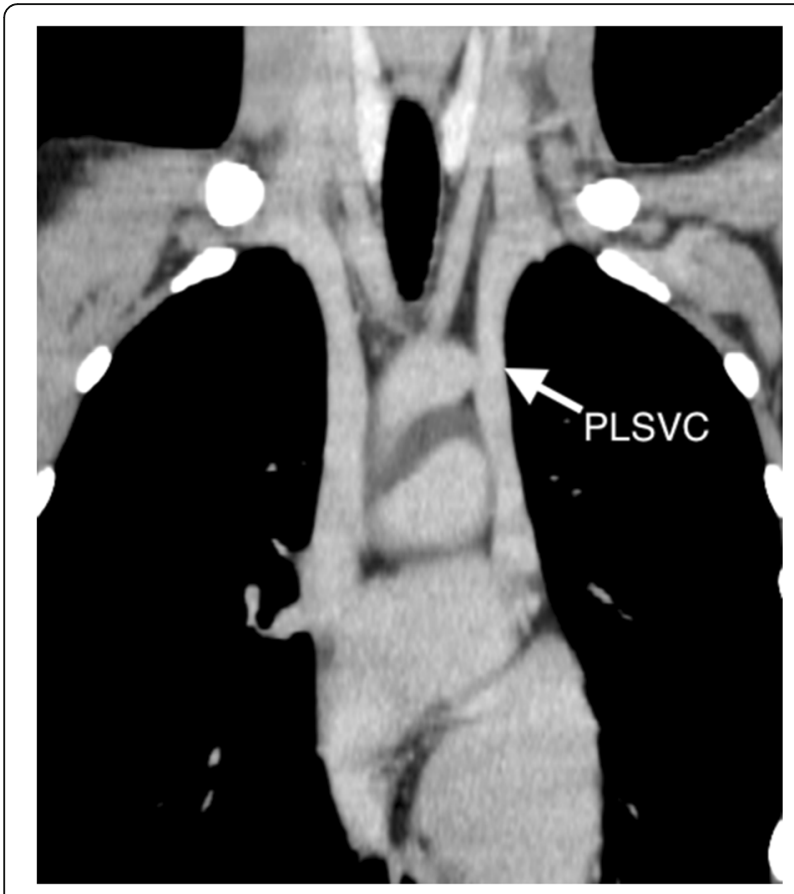

Fig. 1 Preoperative computed tomography shows persistent left superior vena cava (PLSVC) and left brachiocephalic vein atresia

inserting a 21-Fr cannula into the ascending aorta and 24-Fr and 28-Fr drainage cannulas into the right SVC and inferior vena cava, respectively. An additional 28-Fr cannula was inserted into the PLSVC.

Orthotopic heart transplantation was performed with modified bicaval technique. After completion of the anastomoses of the left atrium, pulmonary artery, ascending aorta, inferior vena cava, and right SVC, the transected PLSVC was reconstructed with a 10-mm ringed expanded polytetrafluoroethylene graft, which was passed behind the left ventricle and anastomosed to the free wall of the right atrium (RA) in side-to-end fashion (Fig. 2). The postoperative course was uneventful, and the patient did not experience any complications, including venostasis-related symptoms. He was discharged home 6 weeks after the transplantation. The prothrombin time international normalized ratio was controlled at 1.5 to 2.0. Postoperative enhanced computed tomography revealed good patency of the reconstructed graft 2 months after transplantation (Fig. 3). During 2 years of follow-up, the patient has done well, with good systolic and diastolic function of the transplanted heart and no adverse events.

\section{Discussion}

There are various types of PLSVC. In 92\% of patients, the PLSVC connects to the RA via the coronary sinus (CS) and 65\% of patients have an absent LBCV [6]. Our patient had a left SVC and atresia of the LBCV, which

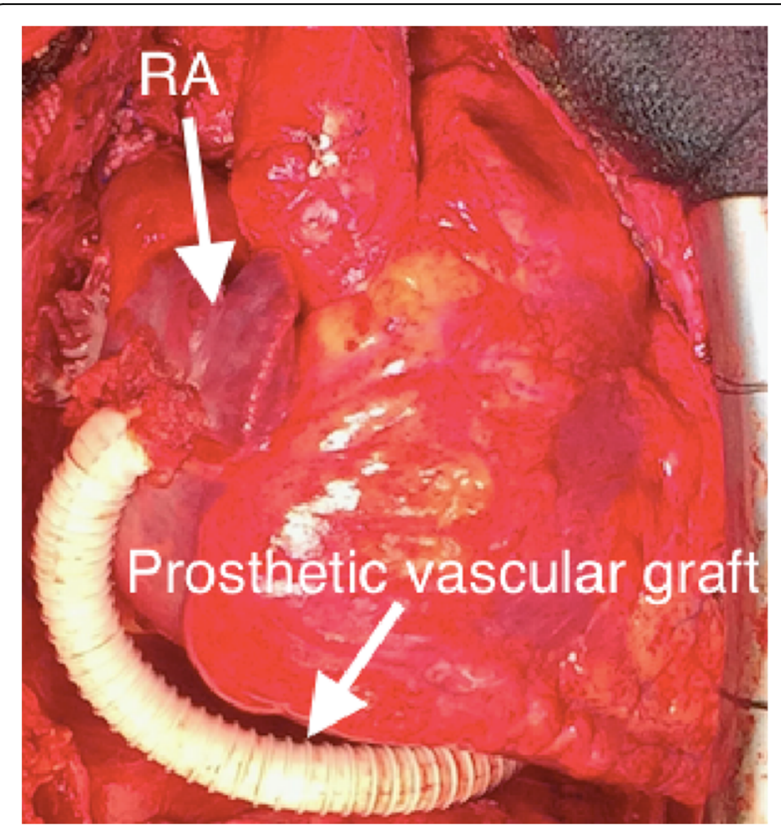

Fig. 2 Intraoperatively, the prosthetic vascular graft from the PLSVC is anastomosed to the right atrium

drained from the left jugular vein and left subclavian vein into the $C S$.

There are various opinions concerning the best way to deal with PLSVC in heart transplantation, depending on the type of PLSVC. In transplant patients with a right SVC and LBCV of adequate size, simple ligation of the PLSVC is acceptable [4]. If the LBCV is absent, the PLSVC should not be simply ligated because this could cause venostasis repercussions, including facial and left upper arm edema [7]. Therefore, several surgical approaches to

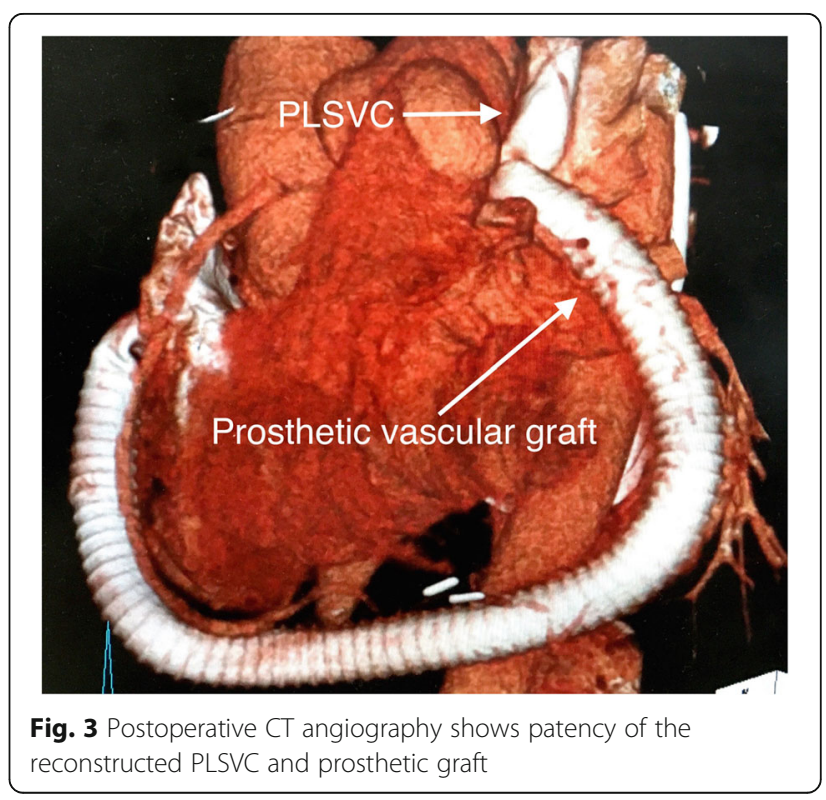


reconstruct the PLSVC have been reported, including the use of a prosthetic vascular graft [3]; modification of the recipient's cardiectomy with preservation of the CS, which is connected to the RA [4]; or harvesting of the donor heart with a long SVC, which is anastomosed to the PLSVC [5].

In our patient, we initially planned to ligate the PLSVC because the right SVC seemed to be larger than the PLSVC. We deemed PLSVC ligation a safe procedure because the innominate vein is sometimes simply ligated and divided to improve access (for example, in aortic arch surgery) without postoperative left upper limb swelling or neurological symptoms [8]. The method of harvesting the donor heart could not be modified in this case because the harvesting procedure preceded the recipient operation. We could not perform modified cardiectomy in the recipient operation because of hard adhesions around the heart, especially on the posterior wall that included the CS, which led to the bridging LVAD implantation while awaiting a donor.

Acute thrombosis and occlusion of the vascular graft is one of the possible postoperative complications and may cause symptoms of acute venostasis. Fortunately, this complication was not observed because we used warfarin to maintain our patient's international normalized ratio of prothrombin time at 1.5 to 2.0. Postoperative enhanced computed tomography revealed good patency of the reconstructed graft, and the patient had experienced no venostasis symptoms.

Thrombotic occlusion of a prosthetic graft anastomosed to the venous system often occurs, regardless of graft size. However, several studies reported that severe complications, such as pulmonary embolism, were rarely observed [9-11]. Although there is no established anticoagulant therapy after prosthetic graft anastomosis to the venous system, warfarinization for 3 to 6 months after surgery has been proposed in several reports [9-11]. The main purpose of PLSVC reconstruction and warfarinization in our patient was to stabilize the perioperative circulation. We predicted that gradual thrombotic occlusion of the graft might occur despite warfarinization. Long-term gradual occlusion of the graft should not cause problems because adequate collateral circulation will likely develop over time. We think that termination of warfarinization at that time could be justified.

Prosthetic graft infection is another possible adverse event because patients must take immunosuppressive agents after heart transplantation. Although our patient has had no episodes of infection to date, careful followup will continue to be necessary.

The advantages of PLSVC reconstruction with a prosthetic vascular graft are that there is no need to change the operative technique on either the donor or recipient side and the procedure is easy to perform. In this case, we did consider anatomical bypass to the right SVC. However, unfortunately, the PLSVC was located behind the left pulmonary artery and in front of the left pulmonary vein. In this situation, we were afraid of graft kinking and/or compression of the pulmonary artery and right ventricle if the reconstructed graft was routed in front of the heart. Therefore, we chose posterior routing as an alternative path. To be sure, the posterior routing risked compression of the pulmonary vein and also had a risk of graft compression by the heart. Therefore, we first anastomosed the ringed graft to the edge of the PLSVC. Then, we checked the graft configuration, including surrounding tissue, and decided to pass the graft posterior to the heart to avoid graft kinking and compression of the pulmonary artery and right ventricle. We thought that anastomosing the graft to the RA free-wall would be easy. Then, we confirmed adequate blood flow through the PLSVC, adjusted the length of the graft posterior to the heart, and performed end-to-side anastomosis. If we had selected anterior graft routing, a longer prosthetic graft would have been needed to avoid heart compression. Another concern is that adhesions around the LV resulting from the prosthetic vascular graft may induce LV diastolic dysfunction. In our patient, followup echocardiography 2 years after transplantation showed good systolic and diastolic function of the transplanted heart. However, careful monitoring of cardiac function will be necessary hereafter.

\section{Conclusions}

We successfully performed heart transplantation with PLSVC reconstruction using a prosthetic vascular graft. We were deeply concerned about the risk of complications. However, the patient's postoperative course has been uneventful 2 years after the surgery, without any venostasis-related symptoms, infections, or diastolic dysfunction. Although careful observation is mandatory, reconstruction of the PLSVC with a prosthetic vascular graft is one option in heart transplantation.

\section{Abbreviations \\ PLSVC: Persistent left superior vena cava; LV: Left ventricular; LVAD: Left ventricular assist device; LBCV: Left brachiocephalic vein; RA: Right atrium; CS: Coronary sinus; RV: Right ventricle; PA: Pulmonary artery}

\section{Acknowledgements}

We thank Nancy Schatken, BS, MT (ASCP), and Rebecca Tollefson, DVM, from Edanz Group (www.edanzediting.com/ac), for editing drafts of this manuscript.

\section{Authors' contributions}

$\mathrm{KH}$ wrote the draft of the manuscript. $\mathrm{HH}$ and $\mathrm{YS}$ revised the article. $\mathrm{KH}, \mathrm{HH}$, and $Y Y$ performed the surgery and contributed to the perioperative care. The authors read and approved the final manuscript.

\section{Funding}

The authors declare that they received no financial support pertaining to this case report. 


\section{Availability of data and materials}

The authors declare that all data in this article are available within this published article.

Ethics approval and consent to participate

Informed consent was obtained from the parents of the patient.

\section{Consent for publication}

Written informed consent for publication of this case report was obtained from the patient.

\section{Competing interests}

The authors declare that they have no competing interests.

Received: 17 January 2020 Accepted: 2 April 2020

Published online: 15 April 2020

\section{References}

1. Biffi $M$, Boriani $G$, Frabetti $L$, et al. Left superior vena cava persistence in patients undergoing pacemaker or cardiovascular-defibrillator implantation: a 10-year experience. Chest. 2001;120:139-44.

2. Sarodia BD, Stoller JK. Persistent left superior vena cava: case report and literature review. Respir Care. 2000;45:411-6.

3. Chang YL, Wei J, Chang CY, et al. Cardiac transplantation in situs inversus: two cases reports. Transplant Proc. 2008;40:2848-51.

4. Rábago G, Martín-Trenor A, López-Coronado JL, et al. Bicaval anastomosis in a heart transplant recipient with left superior vena cava. Ann Thorac Surg. 2002;74:1242-4.

5. Weymann A, Schmack B, Karck M, Szabo G. Orthotopic heart transplantation in a patient with persistent left superior vena cava. Ann Thorac Cardiovasc Surg. 2012;18:554-6.

6. Webb WR, Gamsu G, Speckman JM, et al. Computed tomographic demonstration of mediastinal venous anomalies. AJR Am J Roentgenol. 1982;139:157-61.

7. Raisky O, Tamisier D, Vouhé PR. Orthotopic heart transplantation for congenital heart defects: anomalies of the systemic venous return. Multimed Man Cardiothorac Surg 2006;2006:mmcts.2005.001578.

8. McPhee A, Shaikhrezai K, Berg G. Is it safe to divide and ligate the left innominate vein in complex cardiothoracic surgeries? Interact Cardiovasc Thorac Surg. 2013;17:560-3.

9. Shintani $Y$, Ohta M, Minami M, et al. Long-term graft patency after replacement of the brachiocephalic veins combined with resection of mediastinal tumors. J Thorac Cardiovasc Surg. 2005;129:809-12.

10. Sekine $Y$, Suzuki $H$, Saitoh $Y$, et al. Prosthetic reconstruction of the superior vena cava for malignant disease: surgical techniques and outcomes. Ann Thorac Surg. 2010;90:223-8.

11. Spaggiari L, Magdeleinat $\mathrm{P}$, Kondo $\mathrm{H}$, et al. Results of superior vena cava resection for lung cancer. Analysis of prognostic factors. Lung Cancer. 2004; 44:339-46.

\section{Publisher's Note}

Springer Nature remains neutral with regard to jurisdictional claims in published maps and institutional affiliations.

\section{Submit your manuscript to a SpringerOpen ${ }^{\circ}$ journal and benefit from:}

- Convenient online submission

- Rigorous peer review

- Open access: articles freely available online

- High visibility within the field

- Retaining the copyright to your article

Submit your next manuscript at $\boldsymbol{\nabla}$ springeropen.com 